open $\bigcirc$ Access
Authors' contribution:

A) conception and design of the study

B) acquisition of data

C) analysis and interpretation of data

D) manuscript preparation

E) obtaining funding

Received: 10.10 .2020

Accepted: 30.04.2021

\section{A needs assessment study on refugees' inclusion through physical education and sport. Are we ready for this challenge?}

\author{
Eleftheria Papageorgiou ${ }^{\mathrm{A}, \mathrm{B}, \mathrm{C}, \mathrm{D}} \mathbb{( \mathbb { D }}$, Nikolaos Digelidis $^{\mathrm{A}, \mathrm{D}}$ (D), \\ Ioannis Syrmpas ${ }^{\mathrm{C}, \mathrm{D}} \mathbb{D}$, Athanasios Papaioannou ${ }^{\mathrm{A}, \mathrm{D}, \mathrm{E}}$ \\ Department of Physical Education and Sport Science, University of Thessaly, Trikala, \\ Greece
}

*Correspondence: Eleftheria Papageorgiou, Department of Physical Education and Sport Science, University of Thessaly, Karies, 42100, Trikala, Greece; E-mail: elvira91. pap@gmail.com

\begin{abstract}
In recent years, European countries have become hosting destinations for thousands of people who have been forced to leave their home countries. Greece is one of the main European hosting countries of refugees, especially children. Thus, the pupil population is gradually changing and the need for intercultural education is increasing. Physical education (PE) and sports have been recorded as suitable contexts for this process. However, there are still many challenges present in these contexts. The following study attempts to present the perceptions of PE teachers, coaches, and academics on the inclusion of refugees in PE and sports. Fifteen PE teachers/coaches and academics involved in the field of intercultural education participated in the study. A phenomenological approach was followed through semi-structured interviews. The method of thematic analysis was chosen to analyze the data. While all the participants considered PE and sports to be the most suitable contexts for the inclusion of refugees, they emphasized certain barriers to be overcome: the lack of training for PE teachers and coaches, prejudices of the parents of both natives and refugees, and refugees' socioeconomic status and gender issues. Participants also shared their ideas for an adequate training program to improve PE teachers' and coaches' attitudes and promote their knowledge and skills regarding the inclusion of refugees. The participants underlined the need for intercultural education and well-structured training programs to properly manage culturally diverse environments.
\end{abstract}

Keywords: Intercultural education, physical education, sports, inclusion of refugees

\title{
Introduction
}

Over the past few decades, many countries across the glove have faced challenges related to global mobility. More than one million people arrived in European countries (e.g., Greece, Spain, and Italy) from the Mediterranean Sea (UNHCR, 2015). Due to its extensive land and coastal borders, Greece has become the main entry point (Cheliotis, 2013) for 850,000 refugees and migrants (UNHCR, 2015). More specifically, in 2015 and 2018 more than $60 \%$ and $90 \%$ of the immigrants or refugees who arrived in Greece were Muslims from Syria, Afghanistan, and Iraq (IOM, 2018). Interestingly, 25\% of these people were children (UNHCR, 2015).

Unlike other richer European countries, for most of the $19^{\text {th }}$ and $20^{\text {th }}$ centuries Greece was a country whose citizens moved abroad as economic migrants. Only very recently has the country been transformed into a host country 
for refugees and/or immigrants. The most recent waves of refugees and/or immigrants also coincided with the Greek financial crisis (2009-2020). Consequently, Greece has lacked of the experience, facilities, and resources to support the inclusion of immigrants and refugees (Parthenis \& Markou, 2015). This support is necessary, especially for refugees who have experienced traumatic events and are fleeing conflict zones by moving to Europe. Thus, new social challenges and emerging educational needs have been created (Neftci \& Cetrez, 2017). Based on the findings of Huddleston, Niessen, and Tjaden (2013), the education of refugees and their acquisition of competence in the language of the host country, as well as the elimination of discrimination and racial behavior, play a pivotal role in their effective inclusion. A scientific committee has been established by the Greek Ministry of Education to include refugees in the Greek educational system. Many refugee camps have been created all over the country, and both teachers and NGOs have been invited by the Ministry of Education to act as the connecting link between the camps and schools (Nagy, 2018). Over a limited amount of time, Greece has attempted to adopt the appropriate legislation and strategies to promote the inclusion of refugees and/or immigrants (Parthenis \& Markou, 2015). According to UNICEF (2020), approximately 42,500 refugee and immigrant children are estimated to live in Greece. For the years 2019 and 2020, approximately 13,000 and 8,000 of them, respectively, were enrolled in formal education (Greek Council for Refugees, 2020). Arguably, the inclusion of refugee and/or immigrant children in formal education and social life is a challenge (Nagy, 2018) due to their cultural diversity and individual differences in skills, experiences, and backgrounds (Cerna, 2019). In addition to being a challenging process, inclusion also requires interculturally educated professionals (Grimminger, 2008).

\section{Theoretical framework}

The term "inclusion" has recently been introduced in a similar context as "integration" and "assimilation." It refers to the process by which pupils fit into an educational environment and also takes into consideration the conditions of this environment (e.g., the efforts that are made by the authorities; Kipouropoulou, 2019). Nowadays, "intercultural education" depicts the most appropriate response to the challenges of globalization. It refers to encouraging the interaction of people from different cultural backgrounds not only by eliminating fear and prejudices towards the "others," but also seeing this condition as an opportunity for learning and communication. This kind of education does not demand people to abandon their cultural identity and adopt the beliefs and values of other cultures. Rather, it encourages them to focus on their common characteristics instead of their differences (Portera, 2008). It is also a pedagogical perspective that includes goals, content, teaching methods, materials, and assessment in order to promote universal values (e.g., justice, freedom, and equality in schools and in society; Banks, 2002).

The ability of teachers to effectively deliver a course based on intercultural education requires the design, implementation, and evaluation of this process (Grimminger, 2008). These abilities drive intercultural competence, which refers to the attitudes, knowledge, and skills that physical education (PE) teachers and coaches should have in order to effectively interact with their pupils (Barrett, Byram, Lazar, Mompoint-Gaillard, \& Phillipou, 2014). This kind of competence enables educators to interact, cooperate, and experience intercultural contact through the perspective of personal development (Portera, 2008). Additionally, children may cultivate their intercultural competence only if their educators encourage them to understand and value cultural diversity (Barrett et al., 2014). Consequently, this process leads to inclusive pedagogy (Florian \& Hawkings, 2011), which promotes equal opportunities for all children in the society.

\section{$P E$ and sports as contexts of interest}

According to the International Charter of PE, Physical Activity and Sport, participation in these fields is a fundamental right for all and should play an inclusive role in the daily routine of youth and children (UNESCO, 2015). More specifically, physical activity plays a vital role in the inclusion of refugees (Ley \& Barrio, 2019), both in the context of school (Culp, 2013) and in sport clubs (Whitley, Coble, \& Jewell, 2016). Even though PE and sports are considered important contexts for social inclusion, mutual understanding, and respect of cultural diversity (Azzarito \& Solomon, 2005; Culp, 2013), only limited studies have been conducted in these areas (Amara et al., 2005; Ley \& Barrio, 2019). Some sport educators seem to recognize the importance of intercultural education and their own role in its delivery (Columna, Foley, \& Lytle, 2010). However, several barriers to its implementation have been recorded in the literature (Dagkas, Benn, \& Jawad, 2011; Agergaard, Cour, \& Gregersen, 2015).

The increasing number of refugee/immigrant pupils, many of them being unaccompanied and psychologically traumatized children (Sirin, \& Sirin, 2015), has made the promotion of interaction between different cultures through physical activity an urgent need in many Western countries (Bennet, 2003) and also in Greece (UNHCR, 2015). This research does not intend to fit the incoming population into categories of "refugees" or "immigrants," as these 
distinctions are temporary and depend on the manipulations of the authorities (Crawley \& Skleparis, 2018). The purpose of the current study is to shed light on how stakeholders (PE teachers, coaches, and researchers of sport psychology and education) perceive the extent to which PE and sports can facilitate the inclusion of refugees, the role of intercultural education in this inclusion, and the authorities' contribution to this endeavor.

\section{Cultural diversity in PE}

PE represents a distinctive area within schools focusing on the development of physical skills and social relationships among peers (Hills, 2007). It has been recorded as a tool that opens new horizons to pupils' cultural diversity and acts as a facilitator in the settlement of young refugees (Doherty \& Taylor, 2007) by promoting equal and active participation and mutual acceptance (Azzarito \& Solomon, 2005). PE curricula include physical and sport activities characterized by global rules and terminology, which break down cultural barriers and minimize the importance of linguistic communication (Amara et al., 2005; Ito, Nogawa, Kitamura, \& Walker, 2010). The greatest advantage of PE over other school courses is that its practical and communicative character eliminates cultural differences as neither speaking nor reading are actually needed for participation (Rosenberg, Fejgin, \& Talmor, 2003). However, contradictory results have been identified regarding the significance of language in the inclusion of refugees in this course (Doherty \& Taylor, 2007; Dundar, 2019).

The development of pupils' interpersonal skills (e.g., communication and cooperation; Kaylene \& Rosone, 2015 ) is strengthened by a teaching style that encourages a task-oriented climate (Kouli \& Papaioannou, 2009) and the adoption of an inclusive approach among PE teachers (Derri, Kellis, Vernadakis, Albanidis, \& Kioumourtzoglou, 2014). On the other hand, an overemphasis on competition and social comparison in PE might not facilitate the inclusion of refugees since this reinforces prejudices (Gugutzer, 2008) and creates tension among participants (Krouwel, Boostra, Duyvendak, \& Veldboer, 2006). PE teachers have also reported that limited resources, a lack of training (Chepyator-Thomson, You, \& Russell, 2000; Flory \& McCaughtry, 2011; Grimminger, 2011), and a lack of confidence in their intercultural competence (Gasparini \& Cometti, 2010) diminish their effectiveness with regard to the inclusion of refugees. Furthermore, dress codes, mixed-gender groups (Dagkas \& Benn, 2006), physical contact issues (Caldeborg, 2020), and parental influence (Dagkas, Benn, \& Jawad, 2011) have been recorded as factors that impact the participation of female Muslim refugees in PE. However, researchers (Dagkas et al., 2011) have argued that the adoption of tolerance, flexible teaching approaches, and the involvement of pupils in decision-making could facilitate Muslim girls' participation in PE.

Authorities should undertake actions and provide resources that promote refugees' access to formal education (Bourgonje, 2010), including PE. Therefore, on-site training related to refugee inclusion should be provided for PE teachers so that they may better cope with the diversity of their pupils (Bourgonje, 2010). PE teachers' intercultural competence could be reinforced through their participation in courses/programs that promote intercultural knowledge and skills (Grimminger-Seidensticker \& Möhwald, 2016). Additionally, the aforementioned programs could encourage in-service teachers to change their attitudes and practices, adopt intercultural education in practice (Azzarito \& Solomon, 2005), and recognize the relational aspect of cultural diversity in PE (Leseth \& Engelsrud, 2019).

\section{Cultural diversity in sports}

The participation of youth in sports is mainly a personal choice (Eitzen \& Sage, 2003) and has been positively associated with social behavior, well-being (Bradley, Keane, \& Crawford, 2013; Super, Hermens, Verkooijen, \& Koelen, 2018), and the inclusion of refugees (Spaaij, 2015). Since sports speak a language without words (Schinke, Stambulova, Lidor, Papaioannou, \& Ryba, 2016; Stone, 2018), they can positively contribute to the inclusion of vulnerable populations (e.g., refugees, asylum seekers, immigrants; Doherty \& Taylor, 2007; Whitley, Coble, \& Jewell, 2016), racial equality (Green \& Hardman, 2000), and understanding and respect of cultural diversity (Culp, 2013; Rosenberg, Fejgin, \& Talmor, 2003). Although sports have been described as "well-suited arenas" for promoting social interaction among culturally diverse individuals (Putnam, 2000), young refugees continue to represent a relatively marginalized population in this context (Jae-Pil \& Lyras, 2013) for a variety of reasons. Refugees' socioeconomic background (Walseth, 2007; Agergaard, Cour, \& Gregersen, 2015), natives' prejudices towards refugees (Kunz \& Hanvey, 2000), unfamiliarity with the sport context of the host country (Forde, Lee, Mills, \& Frisby, 2015), and the rules that natives adopt in sports (Kunz \& Hanvey, 2000) have often been recorded as barriers to the inclusion of refugees in sports.

Furthermore, it has been recorded that sports that prioritize competition may exacerbate ethnic tensions and trigger cultural differences (Krouwel, Boostra, Duyvendak, \& Veldboer, 2006). Coaches who create an empowering 
motivational climate foster children's entertainment and social interaction, effectively promote the inclusion of refugees (Doidge, Keech, \& Sandri, 2020), and show empathy and altruism to host populations (Morela, Hatzigeorgiadis, Theodorakis, Goudas, \& Elbe, 2020). However, coaches in many countries have reported that they lack the training, strategies, and appropriate teaching materials to effectively promote the inclusion of refugees (Gasparini \& Cometti, 2010; Forde, Lee, Mills, \& Frisby, 2015).

\section{Research questions}

This study attempts to answer a crucial question: "What needs to be done or what is worth doing for PE and sports to meet the requirements of intercultural education?" We focused on investigating the perceptions of professionals (e.g., PE teachers, coaches, and academics) concerning the following questions:

1. Is the PE context suitable for promoting intercultural education? If so, why?

2. Are sports suitable contexts for promoting intercultural education? If so, why?

3. Which factors facilitate or impede the inclusion of refugees in the context of PE and sports?

4. Do the authorities support PE teachers and coaches with the inclusion of refugees? What additional actions need to be taken in this regard?

\section{Methodology}

The participants in this study were 15 individuals (11 males and 4 females). Eight of them were PE teachers in primary $(n=6)$ and secondary $(n=2)$ schools, and their teaching experience varied between 15 and 25 years. Seven participants were academics and researchers dealing with intercultural education in PE and sports. Their level of experience in this field varied between 2 and 30 years. The PE teachers were randomly recruited from a list of schools attended by refugee children in Central Greece. The academics were intentionally recruited from two universities (Central and North Greece) due to their involvement in projects regarding the inclusion of minorities. All participants had prior coaching experience in one or more sports, and six of them (all PE teachers) were still working as coaches in sport clubs when the interviews took place. The researchers do not seek to separate the participants into groups (PE teachers, coaches, and academics), but rather to highlight the views of professionals involved in the field of organized physical activity (PE and sports) about the phenomenon under investigation. Consequently, the interviews were based on phenomenological narratives in which participants' perspectives of the inclusion of refugees were elicited. Data collection was conducted after receiving approval from the University Institutional Research Ethics Committee. Participants were fully informed of the nature of the study; their participation was voluntary, and written consent was obtained from all participants. Data collection was conducted through face-to-face interviews $(n=13)$ and over Skype $(n=2)$. Skype was used when participants were located far from the researchers, and interpersonal contact was activated remotely in these instances (Sparkes \& Smith, 2014). The interviews were conducted from October to November 2018 and ranged from 20 to 45 minutes long. They were recorded using a voice recorder instrument and were then transcribed by the first author.

\section{Interview design}

In order to fulfill the goals of the present study, a semi-structured interview guide was developed that contained a series of predetermined questions. The content of the questionnaire was identical for the PE teachers/coaches and academics, and adjustments were made as needed depending on the interviewee's characteristics. Both openended and closed-ended questions were included so that participants could freely provide all the information they desired (Turner, 2010). Additionally, open-ended questions were used with the intention of exploring interviewees' perspectives related to their knowledge and experiences in this specific field (Patton, 2002). A short thread of descriptive questions (e.g., years of teaching/research experience with refugees, sport background) was included in the semi-structured interview guide. Individuals were encouraged to share their stories so that their perspectives could be explored and the dimensions of the subject under investigation could be understood (Creswell, 2013). Their anonymity and confidentiality were also declared (Kvale, 1996). Participants' names were replaced by pseudonyms, and correlating acronyms were used ("AR" for the academic researchers, "PET" for the PE teachers, and "PET-C" for the PE teachers/coaches). For example, Agamemnon (AR), Pagona (PET), and Ariadni (PET-C).

The semi-structured interview guide consisted of questions related to participants' perceptions of (a) the inclusion of refugees in PE (e.g., "Which factors do you think act as facilitators of the inclusion of refugees in PE?"), (b) the inclusion of refugees in sports (e.g., "Which factors do you think act as barriers to refugees' inclusion in 
sports?"), and (c) the authorities' support for the inclusion of refugees (e.g., "Do you think that teachers and/or coaches have the appropriate knowledge and skills to facilitate the inclusion of refugees?" and "Have they received training on intercultural education?").

\section{Data analysis}

A qualitative approach using phenomenology was adopted (Sokolowski, 2000) to investigate the lived experiences of professionals (PE teachers, coaches, and academics) regarding the inclusion of refugees in PE and sports in Greece. By employing a qualitative approach, it was possible to include an array of strategies that guaranteed a well-structured study. However, these strategies are not a panacea. Rather, they are helpful for presenting participants' perspectives on a specific subject matter ethically and respectfully (Sparkes \& Smith, 2009). The current study was framed within a relativist ontological framework (Sparkes \& Smith, 2009), and the adopted methods reflect participants' experiences and the researchers' subsequent interpretations (Lincoln, Lynham, \& Guba, 2011).

Hence, the researchers developed the "generating themes" exploring the information related to the research questions (Braun \& Clarke, 2019). More specifically, a total of 122 single-spaced pages of interview transcripts were created by the first author. Then, the first and third author engaged in a collaborative process to produce a thematic analysis of the interview transcripts. According to the guidelines of Braun and Clarke (2012), the present study's coding and analysis combined inductive (Thomas, 2006) and deductive approaches. As the first step, the authors reread the transcripts to become familiar with them and develop independent parallel coding. Then, they temporarily coded the data and generated interpretative labels as initial categories. The coding data were reviewed by the two authors and merged into a compared and overlapped set. When the overlap between categories was low, they conducted further analysis and engaged in discussion to reach a mutual agreement for the creation of potential themes. The potential themes were reviewed in relation to the coding data and the entire data set to ensure they made sense as parts of the broader narrative. After examining the data, all the authors engaged in a retrospective process for the development of the themes. Through discussion and by taking into consideration the specific characteristics of each potential theme, they reached a consensual agreement about the most appropriate themes capturing the essence of the data (Braun \& Clarke, 2006). The themes were thoroughly examined, formally named, and singularly focused. In this phase, quotes were deductively selected from the participants' interviews, and the authors attempted to extract and present the most representative and vivid quotes in relation to the research questions and the literature. The final report emerged from the integrated writing and analysis process with the intention of creating a coherent narrative.

\section{Data trustworthiness}

The trustworthiness of the present study's data was established through (a) well-established research methods; (b) the background, qualifications, and experience of the interviewers; (c) tactics to ensure interviewees answered honestly (Shenton, 2004); (d) the second and fourth author acting in a critical way during the finalization of the themes' development and the selection of the quotes, encouraging dialogue and critical reflection (Sparkes \& Smith, 2009); and (e) "information power" (Malterud, Siersma, \& Guassora, 2016; Braun \& Clarke, 2019).

Similarly, the external reliability of the study was ensured by having the interviews take place (a) in offices or school classrooms so interviewees could feel comfortable, (b) after arranging an appointment with each interviewee and collecting data during formal discussions (LeCompte \& Goetz, 1982), and (c) giving participants the option to withdraw from the interview at any time (Cohen, Manion, \& Morrison, 2007).

\section{Results}

The participants' reports revealed that they shared several common perceptions of the inclusion of refugees as well as some differing perceptions. Five major themes were generated from the thematic analysis of the data: (1) vehicles for intercultural education in PE and sports; (2) key obstacles to the inclusion of refugees in PE and sports; (3) sport clubs: two sides of the same coin; (4) the absence of the authorities; and (5) hints for training programs.

\section{Vehicles for intercultural education in PE and sports}

The responses of the participants indicated that PE and sports can promote intercultural education. More specifically, Aristotelis, Maximos, Themistoklis, Evgenia, Neftonas, Ourania, George, Manolis, Gerasimos, Achilleas, Agamemnon, and Nestoras argued that "the nature and structure of PE and sports encourage social interaction 
among peers, regardless of their cultural identity," as was highlighted by George (AR). Additionally, Neftonas (PET -C) stated that "...there is, in fact, a connection between intercultural education, PE, and sports because pupils feel free to express themselves through rhythmic activities... body language, and motion... to get familiar with cultural diversity... and have fun."

Moreover, Themistoklis, Maximos, Evgenia, Agamemnon, Nestoras, Gerasimos, and Manolis stressed the universal character of the rules governing most sports as an advantage in both contexts, eliminating the difficulties that may arise from speaking different languages. More specifically, Nestoras (AR) claimed that “...children participate more easily in PE or sports, the rules are clear and universally common, allowing children to feel part of a team without needing verbal communication or numerous analyses and explanations." Similarly, Evgenia (PET) claimed, "...rules are the same, balls are the same and that makes it easier for PE and sports to include refugee pupils... There is also the advantage of language, where you need to say nothing but the basics, in order to communicate with others..."

Furthermore, some of the participants (Pagona, Ariadni, and Aris) stated that PE and sports can easily adapt activities from various cultural contexts in order to facilitate the inclusion of refugees. More specifically, Pagona (PET) stated, "The introduction of games, sports, or activities that come from refugees' backgrounds and/or modifications of games and activities that combine elements from diverse cultural backgrounds may help Greek children become more tolerant of and familiar with their diverse peers."

Interestingly, some of the respondents (Themistoklis, Aris, Evgenia, Neftonas, and Agamemnon) argued that well-structured lessons can promote the inclusion of refugees more effectively as, according to Agamemnon (AR), "...games and activities may help pupils to have a specific role, promoting their teamwork and helping both PE teachers and coaches to create a context that urges participants' mutual respect and reflection on their behaviors ..." In conclusion, the respondents argued that respect, responsibility, and cooperation could be developed through PE and sports regardless of the individual's cultural background, naturally promoting the goals of intercultural education.

\section{Key obstacles to the inclusion of refugees in PE and sports}

Although the interviewees reported that PE and sports could effectively promote the inclusion of refugees, there are several barriers that impede this process. The vast majority of the respondents (Aristotelis, Maximos, Ariadni, Aris, Evgenia, Agamemnon, Nestoras, Achilleas, and George) argued that “...there is no official training on intercultural education... the effectiveness of lessons depends enormously on their [teachers'] initiation to learn information relevant to the inclusion of refugees," as Evgenia (PET) pointed out. Additionally, Agamemnon (AR) highlighted that "neither PE teachers nor coaches have received any particular training in this area."

Alternatively, some of the participants (Maximos, Aristotelis, Ariadni, and Manolis) highlighted that PE has a weak influence on pupils' perceptions due to the limited amount of time allocated to PE. As Manolis (AR) stressed, "...Arguably two hours [per week] have a limited effect on the inclusion of refugees..." Some of the interviewees (Aristotelis, Themistoklis, Maximos, Aris, Gerasimos, Agamemnon, and George) reported the involvement of refugees' parents as another barrier to the inclusion of refugees in both PE and sports. For example, Maximos (PET-C) stated, "Parents are the main problem and not children. A lot of parents have prejudices, and they insist on limiting their children's interaction with native children." Some of the participants (Aristotelis, Themistoklis, Maximos, Aris, and Agamemnon) also mentioned that this is a result of the parents perceiving Greece as a temporary residence and thus not choosing to integrate into Greek society. For example, Aristotelis (PET-C) highlighted that "Some of the refugees' parents are trying to leave the country, so they do not really care about their children's inclusion in the educational system. Therefore, this decision has an impact on their children's intention to get involved in PE and sport as well."

Two of the participants (Maximos and Achilleas) highlighted the prejudices of pupils with Greek parents as a barrier to the inclusion of refugees. Achilleas (AR) stated the following:

Parents display huge resistance, and that resistance is conveyed to their children... for example, when you often introduce native pupils to foreign ones, with their parents being absent, native children are likely to be friendly... on the contrary when their parents are present, these children are not friendly anymore... I assume that their parents influence their behavior.

Furthermore, one of the participants also focused on teachers' and coaches' attitudes towards diversity, which affect the behavior of their pupils. Achilleas (AR) argued that "Many times, even teachers or coaches treat people of different cultural backgrounds with suspicion. As a result, their attitudes have an impact on their teaching style and also on pupils' behavior." 
Additionally, some of the participants (Aris, Ariadni, Neftonas, and George) mentioned that even if linguistic communication is not necessary, it is useful for approaching refugees and promoting their inclusion both in PE and in sports. More specifically, Ariadni (PET-C) reported, "the lack of a common language is an issue... we make efforts to approach refugee pupils, to talk to them... but we cannot communicate."

A few of the participants (Neftonas, Ariadni, and Aris) also revealed the lack of proper facilities and equipment as a barrier. For example, Neftonas (PET-C) emphasized, “... the lack of facilities to meet refugee pupils' needs. For example, both in our school and in the sport club there are no locker rooms, and native children come to school or the sport club already wearing their sportswear. However, this is not possible for Muslim girls since they need to wear their special sportswear..."

\section{Sport clubs: Two sides of the same coin}

Focusing specifically on sport clubs, most of the participants (Aristotelis, Maximos, Pagona, Ariadni, Themistoklis, Aris, Evgenia, and Ourania) stated that sports facilitate the inclusion of refugee children. Their main argument is that children are guided towards a well-structured sport context that fosters interaction with their peers. Sharing is also a common goal that requires teamwork, regardless of cultural background. More specifically, Themistoklis (PET-C) stated, "Every child has the opportunity to choose the sport they like and therefore enjoy it and actively participate while sharing common goals. Thus, children can smoothly be socialized and included into society." Ourania (AR) also added that "Sports are organized contexts, and as a result, they can provide a specific direction suitable for every child, also supporting the inclusion of refugees."

Some of the participants (Neftonas, Manolis, Gerasimos, Achilleas, Agamemnon, Nestoras, and George) mentioned specific barriers that impede the inclusion of refugees in sports. For example, Achilleas (AR) underlined the competitive quality of sports, identifying that it "may lead to tensions and disagreements between opposing team members ... This creates a negative mood for the team's members, especially when there are individuals from diverse cultural backgrounds." Furthermore, Neftonas (PET-C) revealed that "...the participation of refugees in sports is not that common, mainly due to financial reasons or transportation problems, both of which make it even more difficult for them to join such settings." Additionally, George (AR) stated the following:

Refugees coming from a cultural context that differs from the Western cultural context may find it difficult to interact within the context of sports. For example, Muslim refugees are likely to be reluctant, and they might feel awkward due to gender issues or dress codes. Thus, they come up with excuses or do not participate, and this situation automatically marginalizes them... and makes them adopt a negative attitude towards the others, affecting the others' attitudes as well...

Some of the participants (Neftonas, Manolis, Gerasimos, and George) also highlighted that sports may help the inclusion of refugees "only in the case that coaches have received the appropriate training to promote mutual interaction, understanding, and support between refugee and native athletes... then the insecurity that foreign pupils may initially feel will be eliminated," as Manolis (AR) pointed out.

\section{The absence of the authorities}

The majority of the participants (Aristotelis, Maximos, Ariadni, Evgenia, Aris, Nestoras, Achilleas, George, Agamemnon, Gerasimos, and Manolis) argued that the state did not provide any on-site training, educational materials, or supporting facilities. More interestingly, Nestoras (AR) stated, “...if I could describe the situation using one phrase that would be authorities" unpreparedness to cope with this challenge... no one could put the blame on teachers or coaches... they could not anticipate that one day they would have to face this emergency situation [a large influx of refugee pupils]." Additionally, Aristotelis (PET-C) stressed that "the state does not organize free seminars or workshops related to the inclusion of refugees... we are trying to cope with their needs based on our knowledge, but this is not enough ... we also need in-service education in order to develop the skills to help these children." Similarly, Maximos (PET-C) stated the following:

I have not received any training to cope with refugees' diversity. For example, I tried to shake hands with refugees, and I noticed that they were reluctant to respond to my gesture. So, I searched online how to deal with this situation. I read about their customs and religious issues to adjust my behavior, but this is not enough. This was the result of my own initiative and not an organized state effort... that is how I... managed last school year...

Interestingly, some of the participants (Maximos, Evgenia, Ariadni, Nestoras, Achilleas, and George) stressed that all educators within the school should be trained to be able to cope with pupils' cultural diversity and facilitate the inclusion of refugees. For example, Ariadni (PET-C) stated, “...it is of high importance for every teacher to re- 
ceive on-site training on intercultural education because we have not attended any course during our undergraduate studies, not even a well-organized seminar. Thus, it is difficult for educators to support the inclusion of refugees."

Although some of the participants (Pagona, Themistoklis, Neftonas, and Ourania) argued that, in the words of Themistoklis (PET-C), "Schools in the given circumstances have supported the inclusion of refugees as well as possible...," Themistoklis (PET-C) also pointed out that "...the years of experience of PE teachers and their knowledge in the pedagogical context helped them to cope with this unexpected situation." Furthermore, Ourania (AR) articulated that PE teachers have open access to knowledge for intercultural education, and it actually depends on their professionalism. More specifically, she stressed the following:

...I believe they [PE teachers and coaches] have it [the necessary educational level] ... after all, there is a variety of books related to intercultural games... there is so much material available... if someone wants to discover the knowledge then they can just read the books.

\section{Hints for training programs}

Participants' perceptions of a well-structured intercultural training program are categorized as promoting attitudes such as "knowledge of ways to eliminate stereotypes," as Evgenia (PET) highlighted, knowledge about "different cultural customs and various games from different cultures," as Agamemnon (AR) pointed out, and skills, referring to "methods or strategies for approaching and including refugee children from a psychological aspect," as Ariadni (PET) mentioned. Gerasimos (AR) also focused on the "...urgent need of training in religious issues such as body contact or nutrition issues that might affect refugees' participation in PE and sports."

The expectations of the aforementioned interviewees are summarized in the following suggestion. An educational system that takes into consideration pupils' heterogeneity, minority diversity, religious diversity, gender relations, and sports culture may facilitate the inclusion of refugees. Additionally, the interviewees proposed that an educational program focused on the aforementioned characteristics should be developed and delivered to every educator and professional working in the context of sport.

\section{Discussion and conclusions}

This study attempted to provide a basis for understanding the implementation of intercultural education and the inclusion of refugees in both PE and sports in Greece. The findings revealed that the vast majority of participants perceived PE and sports as important settings for implementing intercultural education and promoting the inclusion of refugees for a variety of reasons. More specifically, they suggested that the context and curriculum goals of PE promote children's social interaction. Furthermore, they suggested that children can familiarize themselves with refugees' backgrounds through games and sport activities and practice teamwork skills and mutual respect in the process. These findings are aligned with previous studies that have implied the very nature of PE eliminates cultural differences and promotes equal opportunities for all pupils (Azzarito \& Solomon, 2005; Kaylene \& Rosone, 2015). Similarly, participants of the present study reported that sport clubs support the inclusion of refugees, fostering children's communication, satisfaction, and mutual respect through social interaction. These reports are in line with recent studies (Hatzigeorgiadis, Morela, Elbe, Kouli, \& Sanchez, 2013; Ito et al., 2010; Doidge et al., 2020; Morela et al., 2020). Finally, the emerging results of the present study highlight that both PE and sports can promote mutual interaction (Rosenberg, Fejgin, \& Talmor, 2003; Amara et al., 2005) and have a positive impact on the inclusion of refugees depending on teachers'/coaches' delivery style (Kouli \& Papaioannou, 2009; Morela et al., 2020) and training (Columna, Foley, \& Lytle, 2010).

Additionally, participants stressed that PE and sports share common characteristics (e.g., games and activities supported by universal rules), and thus linguistic communication is not necessarily needed in these contexts. Previous studies have had similar findings (Amara et al., 2005; Ito, Nogawa, Kitamura, \& Walker, 2010; Scinke et al., 2016). Participants also argued that $P E$ teachers and coaches can adapt games and activities from refugees' backgrounds to facilitate communication and interaction between refugees and native pupils. A similar conclusion stems from previous reports that the sports context provides coaches with the opportunity to easily adapt cross-cultural activities that may facilitate pupils' familiarization and interaction with their teammates (Amara et al., 2005) and create an enjoyable and welcoming environment (Doidge et al., 2020).

On the other hand, the findings of the present study are similar to those of Olliff (2008), implying that although sports can "provide universal language," the lack of communication between PE teachers/coaches and refugee children may act as a barrier to their inclusion (Doherty \& Taylor, 2007; Dundar, 2019). Additionally, as in a previous 
study (Dagkas et al., 2011), several participants of the present study highlighted parents' prejudices as a barrier to refugees' participation in PE and sports. It was also reported that the lack of equipment and the limited time allocated for PE are factors that could make the inclusion of refugees in PE ineffective; this is also supported by the literature (Flory \& McCaughtry, 2011). Furthermore, some of the participants questioned refugees' ability to access sports facilities due to socioeconomic factors. This issue has also been underlined by other researchers (Walseth, 2007; Flory \& McCaughtry, 2011; Agergaard et al., 2015) arguing that the socioeconomic status of refugees is a significant factor that acts as a barrier to their participation in physical activities. Finally, similarly to another study (Dagkas \& Benn, 2006), participants of this study reported that gender issues such as dress codes, mixed-gender activities, and physical contact issues (Caldeborg, 2020) may impede refugees' participation in sports.

However, some of the participants asserted that sports are not the ideal context for promoting the inclusion of refugees due to the competitive nature of these activities. This perspective echoes the findings of previous studies (Walseth, 2006; Spaaij, 2015) suggesting that sports may lead refugees to become competitive and even increase ethnic tensions (Krouwel, Boostra, Duyvendak, \& Veldboer, 2006). Additionally, Amara et al. (2005) questioned the effectiveness of competitive sports for the inclusion of refugees due to the rules of sports and coaches' lack of awareness of refugees' needs. Interestingly, only one of the participants of the present study reported that teachers' prejudices may influence the inclusion of refugees. However, the fact that all the other participants did not report the prejudices of teachers or coaches may imply the need for more in-depth self-awareness. It also highlights the importance of the development of specific programs for the intercultural preparation of these professionals (Columna et al., 2010). Such programs could increase both the awareness and the improvement of their attitudes towards diversity (Banks, Suárez-Orozco, \& Ben-Peretz, 2016). Participants of the present study also argued that their lack of training (Chepyator-Thomson et al., 2000; Flory \& McCaughtry, 2011; Grimminger, 2011; Gasparini \& Cometti, 2010) and professional development of intercultural competence (Forde, Lee, Mills, \& Frisby, 2015) influenced their ability to cope with refugees' cultural diversity.

The participants' suggestion for the inclusion of intercultural education both in undergraduate studies and in the training of in-service PE teachers is in line with the implications of a previous study (Young, 2010). More interestingly, participants of the present study suggested that the training program include knowledge related to critical awareness, skill development, and strategies for building competence, which is in line with past literature (Chepyator-Thomson et al., 2000; Wyant, Tsuda, \& Yeats, 2020), as is their suggestion that various games and activities from around the world could be effective tools for the development of intercultural competence (Puente-Maxera et al., 2020). An on-site training program with these features could help PE teachers and coaches improve their ability to promote the inclusion of refugees (Derri et al., 2014) and also increase their self-efficacy as professionals (Hermans, 2002). Finally, such a program could be very useful in an educational system where the implementation of intercultural education relies on teachers' initiative and skills (Gropas \& Triantafyllidou, 2011).

Although the general sense captured from the data of the present study was that participants have accepted no official training on intercultural education, they are seeking organized training programs including methods and strategies for the development of the appropriate attitudes, knowledge, and skills to facilitate their role in the inclusion of refugees. Thus, training in intercultural education and also curricula changes are necessary for the elimination of stereotypical behaviors. These changes would also lead to a more inclusive pedagogy through a collective endeavor including every aspect of society. This is still missing not only from PE curriculum, but also from several Greek educational programs and curricula, according to the participants of the study.

\section{Ethics approval and informed consent}

The study was approved by the University Institutional Research Ethics Committee. Informed consent was obtained from all subjects involved in the study.

\section{Competing interests}

There is no conflict of interest in this study.

\section{Funding}

Part of this research was conducted within the requirements of the Erasmus + - project "EDU-PACT: Intercultural Education through Physical Activity, Coaching and Training," which was coordinated by the University of Vienna and financed by the European Commission. 


\section{References}

Agergaard, S., Michelsen la Cour, A., \& Gregersen, M. (2015). Politicisation of migrant leisure: A public and civil intervention involving organised sports. Leisure Studies, 35(2), 200-214.

Amara, M., Aquilina, D., Argent, E., Betzer-Tayar, M., Coalter, F., Henry, I., Green, M., \& Taylor, J. (2005). The roles of sport and education in the social inclusion of asylum seekers and refugees: An evaluation of policy and practice in the UK. Loughborough: Institute of Sport and Leisure Policy, Loughborough University and Stirling University.

Azzarito, L. \& Solomon, M. A. (2005). A reconceptualization of physical education: The intersection of gender/race/ social class. Sport, Education and Society, 10(1), 25-47.

Banks, J. A. (2002). An introduction to multicultural education (3 $3^{\text {rd }}$ ed.). Boston, MA: Allyn and Bacon.

Banks, J. A., Suárez-Orozco, M., \& Ben-Peretz, M. (Eds.). (2016). Global migration, diversity, and civic education: Improving policy and practice. New York, NY: Teachers College Press.

Barrett, M., Byram, M., Lazar, I., Mompoint-Gaillard, P., \& Phillipou, S. (2014). Developing intercultural competence through education. Strasbourg: Council of Europe Publishing.

Bennet, C. I. (2003). Comprehensive multicultural education: Theory and practice ( $5^{\text {th }}$ ed.). Boston, MA: Allyn and Bacon.

Bourgonje, P. (2010, March 15). Education for refugees and asylum seeking children in OECD countries. Education International, 50, 1-12.

Bradley, J., Keane, F., \& Crawford, S. (2013). School, sport and academic achievement. Journal of School Health, 83(1), 8-13.

Braun, V. \& Clarke, V. (2006). Using thematic analysis in psychology. Qualitative Research in Psychology, 3(2), 77101.

Braun, V. \& Clarke, V. (2012). Thematic analysis. In H. Cooper (Eds.), APA handbook of research methods in psychology, 2: Research designs (p. 57-71). Washington, DC: APA Books.

Braun, V. \& Clarke, V. (2019). Reflecting on reflexive thematic analysis. Qualitative Research in Sport, Exercise and Health, 11(4), 589-597.

Braun, V. \& Clarke, V. (2019). To saturate or not to saturate? Questioning data saturation as a useful concept for thematic analysis and sample-size rationales. Qualitative Research in Sport, Exercise and Health, 13(2), 201-216.

Caldeborg, A. (2020). Physical contact in physical education-immigrant students' perspectives. Sport, Education and Society, 26(3), 1-13.

Cerna, L. (2019). Refugee education: Integration models and practices in OECD countries. OECD Education Working Papers, 203, 1-73.

Cheliotis, L. (2013). Behind the veil of philoxenia: The politics of immigration detention in Greece. European Journal of Criminology, 10(6), 725-745.

Chepyator-Thomson, J. R., You, J., \& Russell, J. (2000). In-service PE teachers: Background and understanding of multicultural education. Journal of In-Service Education, 26(3), 557-568.

Cohen, L., Manion, L., \& Morrison, K. (2007). Research methods in education (6 ${ }^{\text {th }}$ ed.). London: Routledge.

Columna, L., Foley, J. T., \& Lytle, R. K. (2010). Physical education teachers' and teacher candidates' attitudes toward cultural pluralism. Journal of Teaching in Physical Education, 29(3), 295-311.

Crawley, H. \& Skleparis, D. (2018). Refugees, migrants, neither, both: Categorical fetishism and the politics of bounding in Europe's "migration crisis". Journal of Ethnic and Migration Studies, 44(1), 48-64.

Creswell, J. (2013). Qualitative inquiry \& research design: Choosing among five approaches (3 ${ }^{\text {rd }}$ ed.). Thousand Oaks, CA: Sage.

Culp, B. (2013). Eliminating barriers to physical activity: Using cultural negotiation and competence. Strategies, 26(3), $35-40$.

Dagkas, S. \& Benn, T. (2006). Young Muslim women's experience of Islam and physical education in Greece and Britain: A comparative study. Sport Education and Society, 11(1), 21-38.

Dagkas, S., Benn, T., \& Jawad, H. (2011). Multiple voices: Improving participation of Muslim girls in physical education and school sport. Sport, Education and Society, 16(2), 223-239.

Derri, V., Kellis, I., Vernadakis, N., Albanidis, E., \& Kioumourtzoglou, E. (2014). The effect of an intercultural physical education program in comparison to the typical one on student's social skills learning. Journal of Human Sport and Exercise, 9(1), 91-102.

Doherty, A. \& Taylor, T. (2007). Sport and physical recreation in the settlement of immigrant youth. Leisure, 31(1), $27-55$. 
Doidge, M., Keech, M., \& Sandri, E. (2020). “Active Integration”: Sport clubs taking an active role in the integration of refugees. International Journal of Sport Policy and Politics, 12(2), 305-319.

Dundar, A. (2019). Impact of physical education lesson on adaptation of Syrian refugee school age children in Turkey. World Journal of Education, 9(1), 266-273.

Eitzen, D. S. \& Sage, G. H. (2003). Sociology of North American sport (7 ${ }^{\text {th }}$ ed.). New York, NY: McGraw Hill.

Florian, L. \& Black-Hawkins, K. (2011). Exploring inclusive pedagogy. British Educational Research Journal, 37(5), 813-828.

Flory, S. B. \& McCaughtry, N. (2011). Culturally relevant physical education in urban schools: Reflecting cultural knowledge. Research Quarterly for Exercise and Sport, 82(1), 49-60.

Forde, S. D., Lee, D. S., Mills, C., \& Frisby, W. (2015). Moving towards social inclusion: Manager and staff perspectives on an award winning community sport and recreation program for immigrants. Sport Management Review, 18(1), 126-138.

Gasparini, W. \& Cometti, A. (2010). Sport facing the test of cultural diversity: Integration and intercultural dialogue in Europe, analysis and practical examples. Strasbourg: Council of Europe Publishing.

Greek Council for Refugees. (2020). Access to education. Retrieved May 12, 2020 from https://www.asylumineurope. org/reports/country/greece/reception-conditions/employment-and-education/access-education

Green, K. \& Hardman, K. (2000). Physical education: A reader. Oxford, UK: Meyer \& Meyer Sport.

Grimminger, E. (2008). Promoting intercultural competence in the continuing education of physical education teachers. In P. Giess-Stuber \& D. Blecking (Eds.), Sport-Integration-Europe. Widening Horizons of Intercultural Education, (pp. 304-315). Schneider-Verlag Hohengehren.

Grimminger, E. (2011). Intercultural competence among sports and PE teachers. Theoretical foundations and empirical verification. European Journal of Teacher Education, 34(3), 317-337.

Grimminger-Seidensticker, E. \& Möhwald, A. (2016). Intercultural education in physical education: Results of a quasiexperimental intervention study with secondary school students. Physical Education and Sport Pedagogy, 22(5), 445-458.

Gropas, R. \& Triandafyllidou, A. (2011). Greek education policy and the challenge of migration: An "intercultural" view of assimilation. Race Ethnicity and Education, 14(3), 399-419.

Gugutzer, R. (2008). The body as a cultural phenomenon. In P. Giess-Stuber \& D. Blecking (Eds.), Sport-IntegrationEurope. Widening Horizons of Intercultural Education, (pp. 207-218). Schneider-Verlag Hohengehren

Hatzigeorgiadis, A., Morela, E., Elbe, A. M., Kouli, O., \& Sanchez, X. (2013). The integrative role of sport in multicultural societies. European Psychologist, 18(3), 191-202.

Hermans, P. (2002). Intercultural education in two teacher-training courses in the north of the Netherlands. Intercultural Education, 13(2), 183-199.

Hills, L. (2007). Friendship, physicality, and physical education: An exploration of the social and embodied dynamics of girls' physical education experiences. Sport Education and Society, 12(3), 335-354.

Huddleston, T., Niessen, J., \& Tjaden, J. D. (2013, April 14). Using EU indicators of immigrant integration. Final Report for Directorate-General for Home Affairs. Brussels: European Commission.

International Organization for Migration (IOM). (2018). Mixed migration flows in the Mediterranean: Compilation of available data and information, December 2018. Retrieved March 18, 2018 from https:/migration.iom.int/sites/default/files/public/reports/Flows\%20Compilation\%20Report_December_2018_0.pdf

Ito, E., Nogawa, H., Kitamura, K., \& Walker, G. J. (2010). The role of leisure in the assimilation of Brazilian immigrants into Japanese society: Acculturation and structural assimilation through judo participation. International Journal of Sport and Health Science, 9, 8-14.

Jae-Pil, H. A. \& Lyras, A. (2013). Sport for refugee youth in a new society: The role of acculturation in sport for development and peace programming. South African Journal for Research in Sport, Physical Education and Recreation, $35(2), 121-140$.

Kaylene, P. \& Rosone, T. L. (2015). Multicultural perspective on the motivation of students in teaching physical education. The International Journal of Social Sciences, 4(1), 115-126.

Kipouropoulou, E. (2019). Primary school teachers' perceptions about refugee children inclusion in Greek schools: Are teachers prepared? Sino-US English Teaching, 16(6), 240-248.

Kouli, O. \& Papaioannou, A. G. (2009). Ethnic/cultural identity salience, achievement goals and motivational climate in multicultural physical education classes. Psychology of Sport \& Exercise, 10(1), 45-51.

Krouwel, A., Boostra, N., Duyvendak, J. W., \& Veldboer, L. (2006). A good sport? Research into the capacity of recreational sport to integrate Dutch minorities. International Review for the Sociology of Sport, 41(2), 165-180. 
Kunz, J. L. \& Hanvey, L. (2000). Immigrant youth in Canada. Ottawa: Canadian Council on Social Development.

Kvale, S. (1996). Interviews: An introduction to qualitative research interviewing. Thousand Oaks, CA: Sage.

LeCompte, M. D. \& Goetz, J. P. (1982). Problems of reliability and validity in ethnographic research. Review of Educational Research, 52(1), 31-60.

Ley, C. \& Barrio, M. R. (2019). Promoting health of refugees in and through sport and physical activity: A psychosocial, trauma-sensitive approach. In T. Wenzel \& B. Drozdek (Eds.), An Uncertain Safety (pp. 301-343). Springer International Publishing AG.

Leseth, A. \& Engelsrud, G. (2019). Situating cultural diversity in movement. A case study on physical education teacher education in Norway. Sport, Education and Society, 24(5), 468-479.

Lincoln, Y. S., Lynham, S. A., \& Guba, E. G. (2011). Paradigmatic controversies, contradictions, and emerging confluences, revisited. The Sage Handbook of Qualitative Research, 4, 97-128.

Malterud, K., Siersma, V. D., \& Guassora, A. D. (2016). Sample size in qualitative interview studies: Guided by information power. Qualitative Health Research, 26(13), 1753-1760.

Morela, E., Hatzigeorgiadis, A., Theodorakis, Y., Goudas, M., \& Elbe, A. M. (2020). Youth sport motivational climate and attitudes toward migrants' acculturation: The role of empathy and altruism. Journal of Applied Social Psychology, $0(0), 1-10$.

Nagy, Z. (2018). From camps to schools: The participation of refugee children in Greek public education. Journal of Modern Greek Studies, 36(2), 373-399.

Neftci, N. B. \& Cetrez, O. A. (2017). Resilience and mental health risks among Syrian refugees in Europe: A cultural perspective. ACTA Psychopathologica, 3(5), 1-4.

Olliff, L. (2008). Playing for the future: The role of sport and recreation in supporting refugee young people to "settle well" in Australia. Youth Studies Australia, 27(1), 52.

Parthenis, C. \& Markou, G. (2015). Intercultural education in Europe: The Greek experience. In M. Catarci \& M. Fiorucci (Eds.), Intercultural Education in the European Context. Theories, Experiences, Challenges (pp. 167-201) London: Routledge.

Patton, M. Q. (2002). Qualitative research and evaluation methods. Thousand Oaks, CA: Sage.

Portera, A. (2008). Intercultural education in Europe: Epistemological and semantic aspects. Intercultural Education, 19(6), 481-491.

Puente-Maxera, F., Méndez-Giménez, A., \& de Ojeda, D. M. (2020). Games from around the world: Promoting intercultural competence through sport education in secondary school students. International Journal of Intercultural Relations, 75, 23-33.

Putnam, R. D. (2000). Bowling alone: The collapse and revival of American community. New York, NY: Simon \& Schuster.

Rosenberg, D., Fejgin, N., \& Talmor, R. (2003). Perceptions of immigrant students on the absorption process in an Israeli physical education and sport college. European Journal of Physical Education, 8(1), 52-77.

Schinke, R. J., Stambulova, N. R., Lidor, R., Papaioannou, A., \& Ryba, T. V. (2016). ISSP position stand: Social missions through sport and exercise psychology. International Journal of Sport and Exercise Psychology, 14(1), 4-22.

Shenton, A. K. (2004). Strategies for ensuring trustworthiness in qualitative research projects. Education for Information, 22(2), 63-75.

Sirin, S. R. \& Sirin, L. R. (2015). The educational and mental health needs of Syrian refugee children. Washington, DC: Migration Policy Institute.

Sokolowski, R. (2000). Introduction to phenomenology. Cambridge, UK: Cambridge University Press.

Spaaij, R. (2015). Refugee youth, belonging and community sport. Leisure Studies, 34(3), 303-318.

Sparkes, A. C. \& Smith, B. (2009). Judging the quality of qualitative inquiry: Criteriology and relativism in action. Psychology of Sport and Exercise, 10, 491-497.

Sparkes, A. C. \& Smith, B. (2014). Qualitative research methods in sport, exercise and health: From process to product. London, UK: Routledge.

Stone, C. (2018). Utopian community football? Sport, hope, and belongingness in the lives of refugees and asylum seekers. Leisure Studies, 37(2), 171-183.

Super, S., Hermens, N., Verkooijen, K., \& Koelen, M. (2018). Examining the relationship between sports participation and youth developmental outcomes for socially vulnerable youth. BMC Public Health, 18(1), 1012.

Thomas, D. R. (2006). A general inductive approach for analysing qualitative evaluation data. American Journal of Evaluation, 27(2), 237-246.

Turner, D. (2010). Qualitative interview design: A practical guide for novice investigators. The Qualitative Report, 15(3), 754-760. 
UNESCO. (2015). International Charter of Physical Education, Physical Activity and Sport. Retrieved January 19, 2019 from http://portal.unesco.org/en/ev.php-URL_ID=13150\&URL_DO=DO_TOPIC\&URL_SECTION=201.html

UNICEF. (2020). Refugee and migrant children in Greece as of 31 January 2020. Retrieved January 5, 2020 from https:// www.unicef.org/eca/media/10861/file

UNHCR. (2015). Global trends forced displacement in 2015, UNHCR. Retrieved April 12, 2020 from https://www.unhcr. org/576408cd7.pdf

Walseth, K. (2006). Young Muslim women and sport: The impact of identity work. Leisure studies, 25(1), 75-94.

Walseth, K. (2007). Bridging and bonding social capital in sport. Experiences of young women with an immigrant background. Sport, Education \& Society, 13(1), 1-17.

Whitley, M. A., Coble, C., \& Jewell, G. S. (2016). Evaluation of a sport-based youth development program for refugees. Leisure/Loisir, 40(2), 175-199.

Wyant, J. D., Tsuda, E., \& Yeats, J. T. (2020). Delphi investigation of strategies to develop cultural competence in physical education teacher education. Physical Education and Sport Pedagogy, 15(5), 525-538.

Young, E. (2010). Challenges to conceptualizing and actualizing culturally relevant pedagogy: How viable is the theory in classroom practice? Journal of Teacher Education, 61(3), 248-260.

This is Open Access article distributed under the terms of CC-BY-NC-ND 4.0 International License. 